\title{
O BRASIL E OS BLOCOS REGIONAIS soberania e interdependência
}

Paulo Roberto de Almeida

\begin{abstract}
Resumo: Ensaio histórico sobre o desenvolvimento da economia mundial, com ênfase no papel desempenhado pelos blocos de comércio na construção da interdependência econômica contemporânea e pelos processos de integração na diminuição relativa da soberania nacional. Análise conceitual e empírica sobre esses processos e seu desempenho como entidades relevantes da economia mundial do começo do século XXI. Palavras-chave: economia internacional; integração e blocos de comércio; Mercosul.
\end{abstract}

Abstract: Historical essay on the development of the world economy, with emphasis on the role played by trading blocks in the creation of economic interdependence. Also examined is the process of integration how it contributes to the relative reduction of national sovereignty. This is a conceptual and empirical analysis of these phenomena and their relevance to the world economy at the dawn of the twenty-first century.

Key words: world economy; integration and trading blocks; Mercosul.

$\mathrm{U}$ ma questão historicamente pertinente, para todos os que se interessam pela evolução de longo prazo da economia mundial, seria inquirir em que medida, neste início de século XXI, ela difere de modo significativo de sua equivalente funcional de 100 anos atrás. Quais seriam os elementos de ruptura e quais aqueles de continuidade que uma apresenta em relação à outra, com base nessa perspectiva histórica secular? Uma primeira mudança de impacto, de natureza mais cultural do que propriamente econômica, poderia ao mesmo tempo ser considerada como apresentando características de continuidade: o capitalismo está novamente sozinho. Depois de um "breve" intervalo de 70 anos, em sua extensão máxima, o modo de produção alternativo, baseado na apropriação supostamente coletiva dos meios de produção, deixa o cenário da realidade para tornar-se uma simples referência histórica e talvez mesmo, dentro de mais algum tempo, um mero objeto de "arqueologia industrial".

\section{DOMINAÇÃO DO CAPITAL: DÉJÀ VU AGAIN?}

A economia internacional voltou a ser basicamente de mercado e os elementos de continuidade parecem, por- tanto, prevalecer sobre os momentos de ruptura. O fim do socialismo e a retomada do processo de globalização teriam recolocado o capitalismo na mesma postura de preeminência ideológica e de dominação material absoluta que ele já ostentava em 1900. Estaríamos assistindo, no que se refere algumas das características desse velho capitalismo, a um revival de valores em princípios que pareciam ter sido aposentados pelo welfare state de meados do século XX. Entretanto, haveria algo de fundamentalmente novo na organização social do modo de produção capitalista, desde que o laissez-faire da belle époque foi deixado de lado pelos requerimentos dirigistas da Primeira Guerra Mundial?

O papel do Estado na economia, obviamente, e provavelmente também o padrão-ouro monetário, sacrificado no altar emissionista do papel-moeda sem lastro aparente, constituem dois desses pontos de ruptura. Entretanto, do ponto de vista estrutural, algo mais mudou no cenário econômico mundial? Aparentemente pouca coisa, a julgar pelo modo de funcionamento e pelos botões de comando da economia capitalista. Com efeito, apesar dos inúmeros choques e transformações estruturais por que passou a economia mundial no decorrer do longo século XX 
econômico, atores relevantes e processos produtivos permanecem basicamente os mesmos do que um século atrás.

O grupo de economias dominantes, por exemplo, que respondia pela maior parte dos fluxos internacionais de bens, serviços e capitais em 1900, continua, com poucas exceções, a dar as cartas do jogo econômico neste início de século XXI, da mesma forma que o sistema produtivo continua a ostentar, grosso modo, os mesmos princípios organizacionais e institucionais. Vejamos, em primeiro lugar, os elementos de continuidade mais de perto.

$\mathrm{Na}$ Europa, com exceção do desaparecimento do Império Austro-Húngaro, que nunca teve características econômicas bem marcadas, os centros de poder econômico são praticamente os mesmos. A Alemanha, que já tinha ultrapassado, em 1900, a economia então dominante, a da Grã-Bretanha, volta a integrar, depois da "segunda guerra de trinta anos", o pelotão das economias dominantes, apesar de amputada de cerca da metade de seu território e população e de reduzida à condição de anã política durante a maior parte do período. Na Ásia, a ascensão do Japão a grande potência econômica foi obviamente confirmada, ainda que as promessas de liderança tecnológica e financeira tenham sido seriamente questionadas na última década do século XX. Cem anos atrás, a Rússia e a China eram economias marginais em escala planetária e assim permanecerão durante quase todo o período: a União Soviética teve muito mais importância na esfera política do que na econômica e o gigante asiático recuperava muito lentamente, no último quarto do século XX, sua condição de maior economia do planeta, que o Império do Meio ostentou até o começo do século XVIII. Os Estados Unidos, convertidos de grande exportador de produtos primários em primeira potência industrial, já na passagem do século XX, permanecerão nessa condição durante todo o período, acrescentando, a partir dos anos 30, o título de primeira potência financeira, ao operar-se, no seguimento da suspensão da conversibilidade da libra em 1931, a passagem à hegemonia financeira do dólar nos mercados financeiros (capitais para empréstimos e investimentos diretos).

Da mesma forma, o velho capitalismo concentrador e desigual, cujos "horrores econômicos" levaram Karl Marx a propor um modo alternativo de produção, volta a manifestar-se em toda a sua pujança criadora e destruidora ao mesmo tempo, retomando aliás o ciclo da internacionalização que tinha sido tão bem analisado, em 1848, pelo autor principal do Manifesto do Partido Comunista. ${ }^{1}$ Nada mudou, praticamente, em relação a especialização produ- tiva, organização da produção e dos mercados, trabalho assalariado e sistemas contratuais, não fosse pelo reforço das atividades do terciário - hoje quase dois terços da economia nos países desenvolvidos - que Marx ignorava totalmente por considerá-las como "não produtivas". Algo mudou, por certo, no panorama geográfico da economia mundial, o que é revelado pela incorporação das últimas terrae incognitae ao movimento do capital, territórios antes reservados ao modo de produção socialista que, ao desaparecer depois de setenta anos, se tanto, de vida "inútil", sempre foi marginal nos campos da tecnologia, das finanças, do comércio e da inovação.

Ainda mais autocentrado e autárquico do que as economias comandadas pelos regimes fascistas do entre-guerras, o socialismo manteve-se - ou foi mantido - à margem da economia mundial. Ainda assim, os sistemas baseados no planejamento estatal centralizado exerceram certa influência no pensamento econômico do século XX, contribuindo para moldar políticas econômicas que tiveram certa ascendência no imediato pós-guerra, como a indução pública dos investimentos, o controle estatal da oferta de "bens públicos" e os novos monopólios nacionais nas esferas de transportes, comunicações, energia, notadamente. Não obstante isso, o planejamento indicativo e o controle estatal praticados em certas economias capitalistas na segunda metade do século foram mais em razão do legado do período de guerra, quando setores inteiros da economia possuindo algum significado estratégico tiveram de ser mobilizados e controlados pelo Estado, do que a algum compromisso ideológico com os sistemas econômicos de tipo nacional-socialista ou comunista. Vale lembrar, também, que a suposta herança keynesiana dos anos 30, teve escassa influência nos padrões de políticas públicas do período anterior à Segunda Guerra Mundial, vindo a florescer, basicamente, nos sistemas de welfare state do pós-guerra. As mudanças políticas então introduzidas, tendo em vista o maior controle governamental sobre o instrumental macroeconômico (demanda agregada, política fiscal, taxa de juros, movimentos de capitais), respondiam mais a preocupações de ordem prática dos políticos e estadistas, acossados pela memória da depressão dos anos 30 , do que às contribuições teóricas do grande pensador econômico britânico.

Em todo caso, no mesmo momento em que o keynesiasmo passou a enfrentar certo declínio intelectual e político, sob o impacto do aríete ideológico do tatcherismo e da reaganomics, inspirados diretamente em Hayeck, jogavam-se algumas pás de terra no caixão do modo de pro- 
dução socialista, falecido mais em virtude da inanição aguda causada por sua inoperância econômica do que pelo vírus da democracia política. Assistiu-se, a partir de 1989, não tanto a um "fim da História", mas a um "fim da Geografia", uma vez que o levantamento das barreiras artificiais ao deslocamento do capital fez surgir, no mesmo movimento, um único "exército industrial de reserva", obviamente representado pela China e seus milhões de coolies do novo capitalismo manchesteriano do século XXI.

Com efeito, o impacto da incorporação dos ex-países socialistas aos circuitos da economia internacional não seria muito grande como produto global (15\%, se tanto, do PIB mundial, em razão de sua baixa produtividade) e menos ainda, em fase inicial, como aumento do comércio (basicamente produtos primários, já que os manufaturados "socialistas" tinham competitividade nula), mas as conseqüências seriam mais relevantes no que tange a divisão internacional do trabalho, com uma expansão em torno de $35 \%$ da população economicamente ativa. Esse incremento do exército industrial de reserva se refletiria no aumento da participação da China nos fluxos de comércio internacional, à medida que ela (ainda formalmente socialista) passa a dirigir para o exterior a produção derivada dos investimentos diretos estrangeiros (grande parte deles da diáspora chinesa no sudeste asiático) que ela passa a acolher em volume expressivo nos anos 90 .

Em que pese, no entanto, a manutenção de um mesmo número definido de atores globais e a persistência de padrões relativamente similares de produção, comércio e finanças, a economia globalizada e interdependente do começo do século XXI apenas aparentemente se assemelha àquela do início do século anterior. A grande diferença manifesta-se no campo geopolítico (ou talvez no domínio geoeconômico), pois o movimento de globalização retomado no último terço do século XX é acompanhado pelos processos de regionalização, destacando-se, nos últimos 40 anos, a formação, consolidação e expansão do bloco europeu - comunidade européia do carvão e do aço, mercado comum, Comunidade, depois União Européia -, que é, de certa forma, o herdeiro coletivo das potências coloniais européias do final do século XIX.

\section{BLOCOS REGIONAIS: CONCEITO E MANIFESTAÇÕES EMPÍRICAS}

Embora a designação de "bloco regional" possa ser aplicada a qualquer grupo de países vinculados pela contiguidade geográfica (blocos asiático, africano ou la- tino-americano) ou por acordos intergovernamentais, de tipo econômico ou político, o termo, em sua acepção restrita, refere-se aos agrupamentos de caráter comercial resultando de um projeto integracionista. São exemplos de blocos regionais a União Européia (UE), o Mercosul e o Nafta, bem como dezenas de outras entidades menos conhecidas. Mesmo se antecedentes existem na antigüidade - Liga Ateniense - ou no começo da Idade Moderna Liga Hanseática, por exemplo -, trata-se de fenômeno recente, coincidindo com a emergência da ordem internacional pós-Segunda Guerra. O processo de formação dos blocos regionais contemporâneos coincide com o desenvolvimento dos processos de integração econômica, cujo primeiro exemplo bem-sucedido foi o Mercado Comum Europeu criado pelo tratado de Roma de 1957, convertido depois em Comunidade Européia e mais recentemente (1992) em União Européia, contendo inclusive dispositivos sobre moeda única.

$O$ conceito de integração econômica aplica-se a entidades de natureza política diversa, com realidades econômicas diferenciadas entre si, mas será melhor percebido se considerado como um processo em etapas sucessivas: área de preferências tarifárias, que comporta a simples redução seletiva de tarifas entre dois ou mais sócios, sem obrigações complementares como política comercial; zona de livre-comércio, que liberaliza completamente o intercâmbio entre membros em um prazo determinado, conservando entretanto cada qual sua própria estrutura tarifária em relação a terceiros países; união aduaneira, que compreende, ademais, a definição de uma tarifa externa comum; mercado comum, que liberaliza completamente o fluxo de fatores produtivos e de pessoas, além de obrigar a adoção de políticas comuns nas áreas comercial, industrial, agrícola e de concorrência, entre outras; união econômica e monetária, que pode comportar, como no caso da UE, a abolição das moedas nacionais em favor de um meio circulante comum a seus membros.

Os blocos regionais organizados em torno de um acordo de integração, como a UE, o Mercosul e o Nafta, apresentam a dupla característica de serem discriminatórios em relação aos países não-membros - isto é, excluindo estes últimos das vantagens e benefícios recíprocos concedidos aos membros, configurando, portanto, uma exceção ao princípio da nação-mais-favorecida (NMF) administrado pelas regras do GATT - e de contribuírem, progressivamente, para o aumento da interdependência econômica global, ao anteciparem e prepararem processos mais complexos e geograficamente mais amplos de 
liberalização comercial e de abertura econômica no quadro do sistema multilateral de comércio, atualmente regido pela Organização Mundial do Comércio (OMC). A multiplicação desse tipo de acordo comercial nas duas últimas décadas do século XX obrigou inclusive essa organização a constituir, desde 1996, um Comitê sobre Acordos Regionais de Comércio, com vistas a monitorar seu desenvolvimento, a examinar sua consistência com as regras do GATT-OMC e a evitar a generalização de práticas excludentes e discriminatórias. Como exemplos dessas práticas podem ser citados os regimes especiais aplicados a determinados ramos da economia - como a Política Agrícola Comum da UE, por exemplo, altamente distorcida das regras multilaterais de comércio -, que resultam em reservas de mercado e dispositivos contrários ao princípio do tratamento nacional, outro dos fundamentos do GATT, com a reciprocidade.

No regime do GATT, os blocos regionais são regidos pelo art. 24, que estabelece as condições pelas quais esses agrupamentos (em geral sob a forma de zona de livrecomércio ou de união aduaneira) podem ser progressivamente constituídos como exceção à cláusula NMF (geralmente no prazo de dez anos), devendo cobrir "substancialmente todo o comércio" entre os membros, sem introduzir maiores barreiras tarifárias e restrições não-tarifárias do que as existentes no comércio desses países com terceiros, anteriormente à criação do novo bloco. Em 2000, existiam no mundo cerca de 130 agrupamentos regionais, e 90 deles tinham sido notificados à OMC depois de sua criação, isto é, 1995. Desse número, seis blocos tinham sido declarados em conformidade com as regras do GATTOMC, mas apenas dois estavam ainda vigentes.

A UE, a mais exitosa experiência de integração econômica conhecida, estabeleceu desde seu início o objetivo do mercado comum (livre circulação de bens, serviços, capitais e pessoas), atingido de forma acabada apenas em 1993, mas convivendo durante muito tempo com espaços econômicos reservados aos nacionais de seus países constitutivos (monopólios estatais ou exceções nacionais em matéria de transportes aéreos, sistemas bancários, meios de comunicação de massa, por exemplo). Já o Nafta é uma simples zona de livre-comércio, embora reforçada por dispositivos liberalizantes abrangentes, cobrindo serviços, investimentos, concorrência, compras governamentais e propriedade intelectual. O Mercosul pretende ser um mercado comum, ainda que em uma modalidade intergovernamental e não sob o formato do direito comunitário como no caso da UE. Entretanto, dez anos depois de sua cria- ção, em 1991, ele ainda não conseguiu realizar plenamente sua zona de livre-comércio ou implementar de maneira integral sua união aduaneira. Os demais exemplos conhecidos de integração combinam elementos de livre-comércio com os de uma simples área de preferências tarifárias, a primeira etapa da construção integracionista.

O modelo europeu de cooperação econômica e de integração comercial - que na verdade começou em 1951 com a Comunidade Européia do Carvão e do Aço (Ceca) - exerceu forte influência em toda a América Latina, tendo inspirado diversos experimentos integracionistas desde os anos de 1960, a começar pela Associação LatinoAmericana de Livre Comércio (Alalc), criada pelo Tratado de Montevidéu desse ano e substituída, vinte anos depois, pela Aladi, que a despeito do ambicioso objetivo integracionista que ostenta no nome não passa de uma simples zona de preferências tarifárias. É no âmbito da Alalc-Aladi que se desenvolvem as experiências sub-regionais de integração, a começar pelo Grupo Andino (criado com o Pacto de Cartagena de 1969), convertido em Comunidade Andina em 1996 (sem que, no entanto, sua pretensão em atingir a fase do mercado comum tenha sido sequer vislumbrada), e sobretudo a do Mercosul, o mais importante bloco de países em desenvolvimento que pretendem, tendencialmente, alcançar um mercado comum. A Aladi, que oferece cobertura jurídica - do ponto de vista das regras do GATT e dos compromissos multilaterais comerciais - a todos os países da região, reagrupa quase toda América do Sul (Argentina, Bolívia, Brasil, Chile, Colômbia, Equador, Paraguai, Peru, Uruguai e Venezuela), mais o México (que solicitou uma derrogação de suas obrigações em relação à cláusula NMF, pelo fato de ter aderido ao Nafta) e, desde 1998, Cuba.

No ano de 1960, criou-se a Associação Européia de Livre Comércio (Efta) com vistas a oferecer uma perspectiva de liberalização dos intercâmbios aos países que não aderiram, em 1957, ao projeto comunitário dos tratados de Roma, em especial o Reino Unido e os países escandinavos. A Efta agrupou, no início, todos os outros países capitalistas europeus que não pertenciam à Comunidade Européia, mas quase todos eles decidiram aderir, aos poucos, ao sistema comunitário, à exceção da Suíça, da Noruega e da Islândia. Data dessa mesma época, o Mercado Comum Centro-Americano (MCCA), que nunca realizou seu objetivo nominal, contentando-se com acordos de livre-comércio com seus vizinhos maiores, como México, Venezuela, Colômbia e também o Chile. México, Venezuela e Colômbia encontram-se por sua vez vinculados, 
desde 1995, no chamado Grupo dos Três (G-3), que visa à constituição de uma zona de livre-comércio num prazo de dez anos.

Ainda no hemisfério americano, cabe reconhecer que o maior agrupamento de todos, o já citado Nafta - assinado em 1992, em vigor desde 1994 entre os Estados Unidos, o Canadá e o México - pode ser estendido a outros países, como revelado em algumas concessões feitas a países do Caribe e da América Central e, sobretudo, na decisão tomada pelos Estados Unidos em novembro de 2000 a fim de negociar um acordo de livre-comércio com o Chile, país que já mantém acordos similares com outros dois membros do Nafta, o México (1992) e o Canadá (1998). Dois pequenos grupos regionais atraem mais a atenção do que efetivamente pesam na balança da região: a Comunidade do Caribe (Caricom), criada em $1995 \mathrm{com}$ o objetivo de constituir um mercado comum, mas que não logrou sequer ser uma zona de livre-comércio; e a Associação dos Estados do Caribe (AEC, 1994), da qual fazem parte inclusive Cuba, os centro-americanos, México e Venezuela, e que se dedica mais à concertação e à cooperação econômica e política.

Na região da Ásia-Pacífico, destacam-se: a Associação das Nações do Sudeste-Asiático (Asean), criada na época da guerra fria (1967) para fortalecer a cooperação política entre países anticomunistas, mas que admitiu, recentemente o Vietnã ainda formalmente comunista e que tenta negociar uma zona de livre-comércio passando por um sistema de preferências tarifárias; a Closer Economic Relations (CER), zona de livre-comércio entre Austrália e Nova Zelândia que pode evoluir para uma união econômica; e a Asia Pacific Economic Cooperation (Apec), fórum de diálogo que associa quase todos os países da bacia do Pacífico (inclusive no hemisfério americano) em um programa de liberalização de comércio e de cooperação econômica. $\mathrm{Na}$ África, a despeito de tantos experimentos, ao longo dos anos, quanto na América Latina, o único bloco regional com viabilidades comerciais - mas inúmeros obstáculos políticos momentâneos - parece ser representado pela Southern African Development Community (SADC), composto por uma dúzia de nações meridionais sob a liderança da África do Sul, e que visa à constituição de um mercado comum em médio prazo.

Na última década do século XX, os dois processos aparentemente contraditórios - mas basicamente complementares - da globalização e da regionalização avançaram de maneira constante e aparentemente bem-sucedida. A UE, instituída pelo Tratado de Maastricht (1992) e constituí- da em união monetária (entre onze membros apenas, em sua fase inicial, entre 1999 e 2001), encontrava-se negociando o ingresso de mais de uma dezena de países da Europa central e meridional e assinou um acordo-quadro de cooperação com o Mercosul (1995), que poderá evoluir para uma zona de livre-comércio. Da mesma forma, o Mercosul multiplicou, em sua fase de união aduaneira (a partir de 1995), os acordos de associação com outros países (Chile e Bolívia, em 1996 e 1997; África do Sul, em 2000) ou grupos de países (Comunidade Andina, em 1998, sem sucesso porém, repetindo-se a iniciativa em 2000 para implementação a partir de 2002).

A CAN partilha de muitas das preocupações do Mercosul nas negociações levadas a efeito no quadro do chamado processo hemisférico, cujo objetivo é a constituição, a partir de 2005, de uma área de livre-comércio do Alasca à Terra do Fogo, concebida segundo o modelo do Nafta. As negociações, lançadas em Miami, em 1994, entre 34 países da região (à exceção de Cuba), foram de fato iniciadas com base na reunião de cúpula de Santiago (1998) e ratificadas em Quebec (2001); se exitosas, elas podem levar à implementação da Alca depois de 2005, embora subsistam vários imponderáveis econômicos - acesso a mercados de produtos agrícolas ou medidas antidumping, por exemplo e políticos - correspondência com movimentos e processos similares de liberalização no âmbito da OMC, iniciativas semelhantes da UE em direção ao Mercosul. Esse bloco, com apoio da CAN, logrou obter, em 1997, na conferência ministerial de Belo Horizonte, que a eventual formação da futura Alca se fizesse segundo o modelo da adição dos esquemas comerciais existentes na região - conceito de building-blocks -, e não pela simples diluição ou integração individual dos países latino-americanos ao acordo do Nafta, como pretendiam então os Estados Unidos.

\section{COMÉRCIO: LIBERALISMO, PROTECIONISMO, MULTILATERALISMO E REGIONALISMO}

Os fluxos de comércio explodiram ao longo do século $\mathrm{XX}$, saindo do quadro dos tratados bilaterais típicos daquele século - com cláusulas condicionais e limitadas de nação-mais-favorecida - para o âmbito dos acordos multilaterais regidos pelo GATT a partir de 1948. Poucas nações, a exemplo da Grã-Bretanha - entre 1856 e a Primeira Guerra Mundial -, praticavam o livre-comércio, mas as barreiras tarifárias e não-tarifárias eram bem menos importantes no século XIX do que vieram a ser na passagem para o século XX e, sobretudo, depois da grande crise de 
1929. Depois do protecionismo dos anos 30, o comércio internacional cresceu a ritmos sustentados no pós-guerra, atuando como indutor de modernização tecnológica e de ganhos de competitividade. De fato, o ritmo de expansão do comércio internacional, nesse período, apresentou taxas consistentemente superiores ao crescimento do produto global, evidenciando o aumento da especialização, a diminuição dos custos de transportes e uma estratégia de market sharing por parte das empresas transnacionais.

Elas são, na verdade, as grandes responsáveis, a partir dos anos 50, pelo aumento do comércio mundial, que, à diferença do início do século XX, não mais se reduzia à troca de produtos acabados entre economias nacionais, mas passou a ser cada vez mais dominado pelo intercâmbio de produtos semi-acabados e de componentes, que são exportados, não mais para "países", mas para outras firmas, muitas vezes afiliadas ou subsidiárias das primeiras. A partir do quarto final do século $\mathrm{XX}$, um terço, senão mais, do comércio internacional passou a ser realizado entre as próprias firmas multinacionais, em geral no sentido Norte-Norte, já que o comércio Norte-Sul continua a ser dominado por um padrão mais tradicional de trocas, envolvendo matérias-primas e commodities contra manufaturados e outros produtos de maior valor agregado.

Por outro lado, uma parte desse intercâmbio também começou a ser realizado ao abrigo de sistemas preferenciais, como são os esquemas de integração e os blocos de comércio, seja no formato mais simples das zonas de livre-comércio, seja nos mais sofisticados de tipo mercado comum ou união monetária. Esses arranjos econômicos, sancionados ou não pelo sistema multilateral de comércio regido pelo GATT, começaram a ser feitos, em certa medida, para contornar obstáculos não-tarifários que passaram a ser erigidos à medida que as rodadas de negociações multilaterais do GATT foram reduzindo, em níveis geralmente insignificantes, as tarifas aplicadas a bens industriais pelos países mais avançados. Em determinado momento, o desarme tarifário deu lugar a discussões sobre obstáculos não-tarifários e outras medidas não quantificáveis - chamadas de "zona cinzenta" - cujo impacto cresceu valendo-se do momento em que novos competidores agressivos, como os países emergentes da periferia capitalista, passaram a oferecer uma gama mais ampla de produtos de melhor qualidade nos mercados mundiais.

O protecionismo comercial pode ser ocasional e sujeito a lobbies setoriais que fazem pressão pela defesa de empregos em determinadas indústrias - como nos EUA, onde ele em geral assume a forma de abusivas medidas antidumping ou dos direitos compensatórios - ou institucionalizado e sistemático, como no caso da "Política Agrícola Comum" da União Européia, baseada em mecanismos complexos de proteção à produção local - via subsídios à produção e restrições quantitativas, como quotas e picos tarifários contra as importações - complementada pela competição desleal no comércio externo, mediante subvenções ilegais às exportações. Geralmente aplicado ao setor agrícola ou no caso de algumas indústrias tradicionais não competitivas - siderúrgicas, têxteis, calçados -, o neoprotecionismo dos países desenvolvidos subtrai aos países emergentes e em desenvolvimento o benefício que eles poderiam retirar do comércio exterior enquanto fator indutor de crescimento e de transformação estrutural de suas economias.

Alguns mecanismos compensatórios foram desenvolvidos a partir dos anos 50 e sobretudo nos 60 para integrar de forma mais completa os países em desenvolvimento na economia mundial. Eles se manifestam no sistema geral de preferências - pelo qual os países industrialmente avançados fazem concessões tarifárias àqueles menos avançados, sem exigir compensações em troca - e em alguns acordos concessionais que tendem a reproduzir antigas relações de dependência formalmente abolidas com a descolonização. A conferência das Nações Unidas sobre comércio e desenvolvimento - UNCTAD - tentou consagrar, nos anos 60 e 70, formas mais avançadas de relacionamento comercial, financeiro e tecnológico entre países ricos e pobres que pudessem institucionalizar, por meio de acordos multilaterais, o princípio do tratamento diferencial e mais favorável em favor dos últimos, mas os primeiros sempre manifestaram preferência por arranjos mais flexíveis, caracterizados pela concessionalidade unilateral e seletiva (inclusive do ponto de vista político). Práticas discriminatórias e modalidades pouco transparentes de acesso a mercados continuam, portanto, a marcar o comércio internacional, a despeito do grande progresso que se logrou quando, no final da Rodada Uruguai de negociações comerciais multilaterais, se passou, em 1995, do regime mais "permissivo" do GATT-1947 para os mecanismos mais estritos do GATT-1994 e da OMC.

Não obstante isso, o tratamento discriminatório manifesta-se sobretudo sob a forma dos esquemas de integração, geralmente entre países vizinhos. Os blocos regionais de comércio adotam como ponto de partida a contigüidade geográfica para desenvolver mecanismos preferenciais de acesso aos mercados dos países-membros, mas a maioria limita-se a esquemas pouco elaborados, ao estilo das zonas de livre-comércio como o Nafta (embora 
ele contemple arranjos reforçados em serviços, investimentos e propriedade intelectual). Alguns blocos comerciais avançam a ponto de se converter em mercados comuns (como pretende ser o Mercosul, que ainda precisa completar sua união aduaneira) e apenas um, a União Européia, consolidou seu mercado comum e deu passos decisivos para converter-se em união econômica e monetária, tendo adotado inclusive uma moeda comum, o euro.

Os blocos comerciais tornaram-se importantes atores da economia internacional, justificando-se que a OMC tenha decidido instituir, um ano após sua criação, um comitê dedicado a monitorar suas atividades, de maneira a assegurar que esses arranjos - que, por sua natureza discriminatória, podem desviar fluxos de intercâmbio - preservem a compatibilidade com as regras do sistema multilateral. Em todo caso, na passagem do século XX para o XXI, o processo de liberalização comercial poderia ser impulsionado tanto pelas rodadas multilaterais administradas pela OMC, cuja estrutura é formalmente igualitária, como pelos mecanismos geograficamente restritos dos blocos comerciais.

Entre eles, o Mercosul - uma bem-sucedida experiência político-econômica e o mais importante esquema de integração entre países em desenvolvimento - parece ameaçado de ser colocado em situação de diluição comercial antecipada sob pressão da Alca (Área de Livre-comércio das Américas), projeto que envolve todo o hemisfério (com exceção de Cuba). Criado pelo Tratado de Assunção de 1991, o Mercosul juntou numa mesma união aduaneira com a perspectiva de se avançar para um mercado comum - as economias da Argentina, do Brasil, do Paraguai e do Uruguai, aos quais se associaram, mediante um acordo de livre-comércio de 1996, Chile e Bolívia. Como resultado de uma reunião de chefes de Estado dos países da América do Sul em Brasília, em setembro de 2000, negociações estavam sendo travadas para a conformação de um espaço econômico integrado nesse continente até 2005, unindo os países do Mercosul e os da Comunidade Andina.

\section{ALCA: FIM DA SOBERANIA ECONÔMICA BRASILEIRA E DESAPARECIMENTO DO MERCOSUL?}

Admitindo-se que a opção pelo estabelecimento de um espaço integrado em seu imediato entorno geográfico, tal como evidenciado na experiência do Mercosul, constitui uma das principais vertentes da estratégia brasileira de inserção econômica internacional na atualidade, pode-se perguntar em que o desenvolvimento dessa modalidade restrita de interdependência econômica contribui para o fortalecimento de sua economia e como a irrupção da proposta da Alca pode, ao contrário, enfraquecer a "soberania" econômica do Brasil e colocar em perigo as fundações do Mercosul. Registre-se que as questões mencionadas já comportam uma opção de princípio pelo Mercosul e uma recusa apriorística da Alca, como parece ocorrer com a maior parte dos atuais comentaristas da economia brasileira.

Com efeito, muitas das questões que cercam o debate sobre as vantagens e desvantagens da Alca para o Brasil e o Mercosul vêm sendo contaminadas por uma espécie de parti pris ideológico, ou seja, uma posição de princípio que, por um lado, tende a recusar, em caráter absoluto, os fundamentos e as implicações econômicas da zona de livre-comércio hemisférica, aceitando, por outro lado, a estratégia política de "menor custo" do Mercosul para a economia brasileira ou a opção pela associação desse bloco com a supostamente mais benigna União Européia. São politicamente realistas ou economicamente racionais tais pontos de vista e correspondem aos interesses bem pensados da sociedade brasileira, que parece ter chegado a uma nova etapa de sua transição para a modernidade?

Essa não é a postura assumida neste ensaio, que propugna um exame ponderado de cada um dos elementos em jogo, que tem em vista exclusivamente a formulação da melhor estratégia possível de inserção econômica internacional do Brasil. Caberia discutir cada um dos argumentos favoráveis ou contrários à Alca, tentando separar o que se apresenta como realidade econômica decorrente da liberalização, ou seu possível desdobramento, do que se poderia classificar como posicionamento político em relação ao projeto proposto pelos EUA para o continente. Outra distinção importante a ser feita é a que se refere ao que se poderia chamar de "componentes estruturais da Alca" - seus elementos "imanentes", em linguagem kantiana - e a simples mecânica do processo negociador, que vem-se desenvolvendo desde a segunda metade dos anos 90 e promete estender-se até o início de 2005, pelo menos, segundo o que foi acordado em nível ministerial em Buenos Aires e ratificado na cimeira de Quebec, em abril de 2001.

Com efeito, até a conclusão dessas negociações, cujos contornos específicos dependem muito do conteúdo do mandato negociador a ser atribuído pelo Congresso ao Executivo dos Estados Unidos, torna-se difícil especular sobre benefícios e ameaças da Alca para a economia do 
Brasil e para o esquema do Mercosul. Pode-se no entanto antecipar, com base nas evidências até aqui demonstradas, que o legislativo e os negociadores americanos vêem a construção da Alca como mero resultado da derrubada de barreiras latino-americanas aos produtos e serviços dos EUA, cabendo-lhes bem pouco fazer com suas próprias barreiras, senão a eliminação geral, com as exceções de praxe, das tarifas em geral baixas aplicadas na importação de produtos. Essa não tem sido a visão da diplomacia brasileira, que procura colocar na mesa de negociações outros elementos importantes com vistas a lograr um acordo final mais equilibrado, não apenas em relação ao acesso a mercados - em que são evidentes diversos focos setoriais de protecionismo americano - mas também no que se refere a normas e disciplinas de política comercial, terreno no qual são igualmente claras as restrições aplicadas a produtos estrangeiros no mercado americano.

Um ponto precisa ficar claro no debate que se vai seguir. A compreensão do que seja um acordo de livre-comércio varia muito de perspectiva, segundo se faça uma análise acadêmica dos resultados da abertura econômica e da liberalização dos mercados ou se parta de evidências mais empíricas resultantes de um processo negociador concreto. Na primeira visão, de modo geral de cunho economicista, a liberalização comercial, quaisquer que tenham sido sua amplitude e distribuição entre parceiros, é vista como positiva, pois que conduzindo a uma alocação ótima de recursos e uma utilização mais eficiente da dotação em fatores. Na segunda perspectiva, pode-se dizer que não existe, para a maior parte dos negociadores, essa figura utópica do "livre-comércio", um conceito puramente imaginário que só se materializa nos escritos dos teóricos acadêmicos, mas na verdade dotado de pouco embasamento prático; para eles, trata-se de lograr a melhor situação possível de reciprocidade no processo de abertura comercial, administrando áreas de liberalização progressiva em função das vantagens percebidas ou aparentes. Trata-se de um dilema teórico-prático que não poderá ser resolvido no presente texto, que tem apenas o objetivo de oferecer alguns elementos de reflexão sobre as opções do Brasil e do Mercosul na presente fase de discussões sobre a consolidação interna e o aprofundamento do bloco sub-regional em face da opção hemisférica representada pela Alca.

A discussão pode ser organizada em torno de algumas perguntas fundamentais, as mesmas que vêm sendo repetidamente colocadas pelos representantes dos meios de comunicação aos negociadores e estudiosos acadêmicos do processo hemisférico.
A Alca é desejável, benéfica ao Brasil, funcional para seus objetivos de desenvolvimento econômico e social? - A Alca representa uma espécie particular no gênero integracionista, tratando-se de um processo de liberalização controlada dos mercados e de abertura administrada da economia que já vem sendo aplicado pelo Brasil desde que ele assumiu compromissos negociais nesse sentido em princípios dos anos 60 (criação da Alalc) e, com maior ênfase, com base nos esquemas bilaterais de integração com a Argentina (1986-88) e, de forma quadrilateral, com os demais parceiros do Mercosul (1991). Os cálculos sobre custos e benefícios desse gênero de abertura foram conduzidos de forma mais ou menos empírica pelos responsáveis políticos e econômicos em cada uma dessas oportunidades e julgados compatíveis com as necessidades de desenvolvimento do Brasil, ainda que em nenhum dos casos se tenha alcançado a liberalização total e a integração completa dos mercados.

Do ponto de vista estrito do desempenho ótimo das oportunidades econômicas, toda experiência de integração, ainda que na forma simplificada da eliminação de barreiras aduaneiras sob um regime de livre-comércio, é desejável, quanto a uma situação de plena autonomia econômica, pois que corresponde a uma etapa inicial de liberalização de mercados e de inserção nos circuitos da interdependência mundial, mesmo em um âmbito geográfico mais restrito. Os economistas, procedendo a uma simulação teórica de caráter extremo, recomendariam aliás uma liberalização unilateral erga omnes, isto é, conduzindo à plena integração com o mundo, pois que permitindo nesse caso o livre fluxo de fatores e uma alocação ótima das dotações econômicas. Esse tipo de exercício ricardiano não foi contudo tentado por nenhum país da era moderna, tendo apenas se manifestado de maneira mais ou menos abrangente sob o capitalismo de vanguarda da Inglaterra vitoriana. Desde então, as experiências de liberalização têm sido conduzidas sob forma condicional e restrita, tendo alcançado maior desenvolvimento na Europa ocidental, nos diversos esquemas ali conhecidos desde o final dos anos 40 (no Benelux, na Ceca, na Comunidade Européia, na Aelc, na União Européia, notadamente). Todos esses exemplos têm confirmado empiricamente os pressupostos teóricos traçados pelos economistas sobre os benefícios da liberalização ampliada.

Não deveria, portanto, ser diferente para o Brasil, tanto no formato mais restrito do Mercosul como no esquema ampliado de uma futura Alca, ainda que não se possa arriscar previsões mais positivas quanto a seu caráter fun- 
cional, ou não, para seus objetivos de desenvolvimento econômico e social. Em princípio, a resposta é positiva, ainda que de forma indireta, uma vez que a integração e a liberalização produzem situações de maior eficiência alocativa, conduzindo ipso facto ao aumento da produtividade, à expansão do emprego e à elevação dos níveis de remuneração. Deve-se no entanto observar que o processo de liberalização comercial, estrito senso, não tem como missão histórica "produzir" desenvolvimento, isto é, provocar transformações estruturais na formação social que envolve o sistema econômico, mas tão-somente produzir maior eficiência produtiva, o que por si só não gera distribuição de riqueza ou justiça social. A agenda desenvolvimentista é algo mais amplo que a forma de organização social da produção, implicando em um complexo jogo de fatores políticos e sociais que ultrapassam em muito as possibilidades transformadoras da abertura econômica e comercial.

Resumindo: a Alca pode ser benéfica para o Brasil, mas não se deve esperar que ela resolva todos os nossos problemas de desenvolvimento econômico e social no curto ou médio prazo; estes só podem ser encaminhados internamente, com a mobilização de outros vetores de transformação estrutural - educação, capacitação profissional, investimentos em ciência e tecnologia, modernização institucional, etc. - , não de maneira exógena quando de um impulso originado no entorno econômico externo.

Mercosul e Alca são compatíveis entre si?; a Alca não pode simplesmente dissolver o Mercosul e condená-lo ao desaparecimento enquanto experimento sub-regional? - Em princípio, Alca e Mercosul são plenamente compatíveis entre si e até complementares, uma vez que os esquemas de livre-comércio, mesmo baseados em processos negociais autônomos e independentes, tendem a se reforçar mutuamente e a produzir eficiências dinâmicas que potencializam os ganhos alocativos. No que se refere especificamente ao caso desses dois esquemas americanos, pode-se argumentar que uma zona de livre-comércio maior tende a absorver e a diluir a menor, que foi o que ocorreu, comparativamente (no gênero união aduaneira), entre o Benelux e a Comunidade Européia no decorrer dos anos 70 e 80.

Esse não deveria ser o destino, porém, do Mercosul, que corresponde a uma etapa superior da família integracionista, suplementando seu compromisso de livre-comércio com as obrigações de uma união aduaneira (tarifa externa comum, política comercial comum) e visando alcançar, num horizonte histórico ainda indeterminado, uma situação de mercado plenamente unificado. De maneira que o Mercosul sobreviveria e até poderia aumentar seu grau de coesão interna ao enfrentar o desafio de uma zona de livre-comércio envolvente, mesmo se no caso da Alca trata-se, potencialmente, de uma "super" zona de livre-comércio, compreendendo aspectos pouco usuais nesse gênero de exercício (como compromissos em matéria de propriedade intelectual, política da concorrência, compras governamentais e outros compromissos setoriais não estritamente comerciais). Na prática, é evidente que o "mercado comum do Sul" não passa, atualmente, de uma zona de livre-comércio deficiente e incompleta, pois que prejudicada pela existência de alguns setores restritos à abertura interna recíproca e de outros funcionando sob regime de comércio administrado. Sua união aduaneira "em fase de implementação" é consistente com os pressupostos teóricos e empíricos desse tipo de esquema, pois que tendo de conviver com exceções nacionais à tarifa externa comum, regimes comerciais específicos a algumas situações nacionais "temporárias e excepcionais" e de fato carente de uma administração aduaneira uniforme e dotada de regras claras (falta de um código aduaneiro ou disposições quanto à arrecadação fiscal, por exemplo).

Ainda assim, mesmo que o comércio intra-Mercosul seja absorvido e dissolvido no esquema mais amplo da Alca, o Mercosul tenderá a sobreviver como construção institucional, pois que resultando de uma decisão política no mais alto nível, que aponta para sua progressão contínua, ainda que lenta e por vezes intermitente, em direção de um mercado comum e talvez até mesmo de uma união econômica, a exemplo da Europa de Maastricht (pelo menos no que se refere à união monetária). Os perigos que cercam sua evolução comercial derivam mais dos desafios competitivos associados ao pólo econômico dominante e da força centrífuga do dólar dos EUA, do que da Alca em si, que seria pouco relevante se fosse hipoteticamente subtraída a potência hegemônica. Contudo, mesmo nessa situação extrema de eventual inoperância econômica do Mercosul em razão da preeminência absoluta dos EUA no esquema hemisférico, o projeto sub-regional do Cone Sul tende a sobreviver, pois que ele compreende bem mais do que simples compromissos liberalizadores, estendendo-se a entendimentos sociais, administrativos e de políticas setoriais outras que as meramente econômicas (justiça, turismo e cultura, ciência e educação, previdência social, entre várias outras), o que justificaria a continuidade desse projeto político e societal.

Resumindo: a Alca representa um enorme desafio para a continuidade e para a afirmação da personalidade do 
Mercosul, mas a sua dissolução só se daria por expressa decisão e vontade dos dirigentes políticos dos países-membros, não em função da criação e implementação plena de uma zona de livre-comércio hemisférica, que de forma alguma eliminará, ao contrário até estimulará, o desenvolvimento de outras vertentes integrativas entre os países-membros e associados do Mercosul. Este tem um capital político e uma cultura própria que jamais serão alcançados no plano hemisférico, por mais poderosa e abrangente que venha a ser a Alca no domínio econômico e comercial.

O projeto da Alca não representa uma ameaça fundamental às economias do Brasil e do Mercosul, pelo fato de que sua vocação liberalizadora vai além da agenda tradicional de uma zona de livre-comércio, ou devido a que os elementos de assimetria estrutural são extremamente relevantes quando confrontados ao cenário mais homogêneo da América do Sul ou à dimensão mais modesta de todas as outras economias hemisféricas, à exceção dos EUA? - Sem dúvida que a pauta negociadora da Alca vai muito além do que vinha sendo aceito como a agenda "normal" de uma zona de livre-comércio - compreendendo apenas liberalização do intercâmbio de bens, mais algumas disposições de caráter aduaneiro para evitar triangulação indevida -, abrangendo serviços, propriedade intelectual, compras governamentais, investimentos e outros aspectos menos relevantes, segundo um programa de abertura e de regulação que já se convencionou chamar de "OMC plus". Pode-se no entanto argumentar que a Alca apenas antecipa, ou acelera, esses aspectos pouco usuais das "velhas" zonas de livre-comércio e que tanto o Brasil como o Mercosul encontrariam a mesma pauta de reivindicações liberalizantes numa próxima rodada de negociações comerciais multilaterais ou se decidissem empreender esforço similar com outros esquemas regionais (como a CAN, a UE ou outros grupos de países).

Nem tudo porém é tão-somente uma questão de tempo, já que a ambiciosa agenda da Alca certamente coloca desafios de monta aos países do Cone Sul, em especial no que se refere aos diferenciais de competitividade nos diferentes setores que serão presumivelmente incorporados ao esforço liberalizador hemisférico (serviços, compras governamentais, investimentos, por exemplo). Todavia, deve-se observar que os mesmos temas encontram-se previstos no exercício interno ao Mercosul, processo extremamente complexo e tematicamente diversificado, a despeito mesmo do pequeno número de países engajados e da dimensão mais modesta de seus aparelhos produtivos e de serviços, em grande medida voltados para os próprios mercados nacionais. Mais uma vez neste caso, a Alca coloca ao Mercosul o desafio de seu próprio aprofundamento interno, preservando áreas de preferência sub-regional em um cenário mais amplo de liberalização progressiva no plano hemisférico. A homogeneidade cultural e a intensidade de vínculos intra-Mercosul deve atuar em seu benefício, estimulando negócios no âmbito sub-regional mesmo em face de oportunidades ou desafios potenciais no cenário continental mais vasto.

Alternativamente, os perigos presumidos ou efetivos para o Mercosul derivados do esquema da Alca poderiam ser pressentidos de acordo com as assimetrias fundamentais que caracterizam as economias do hemisfério, não apenas como dimensão bruta (a chamada economia de escala), mas essencialmente em razão dos diferenciais intrínsecos de produtividade e de capacidade de penetração mercadológica. Ainda aqui, os perigos são mais supostos do que reais, uma vez que algumas vantagens comparativas naturais e dinâmicas dos países do Mercosul podem servir de contrapeso ou atuar em seu benefício, no confronto com a potência avassaladora do gigante do Norte. É de se esperar, por exemplo, que mesmo depois de empreendido sério esforço de modernização produtiva e de aggiornamento tecnológico por parte dos países do Mercosul, os diferenciais de produtividade permanecerão importantes em relação àqueles observados em setores de serviços e ramos industriais nos quais os EUA já detêm uma liderança incontestável. Mesmo nesse caso, os diferenciais de custos de mão-de-obra para serviços associados, particularidades dos mercados locais, diferenças ou especificidades culturais, assim como o simples fator da proximidade geográfica atuarão em benefício do Brasil e do Mercosul para ampla gama de bens e serviços, produzindo portanto atração de investimentos e transferência de tecnologia em um horizonte de tempo indeterminado depois de começada a implantação da Alca.

Em análise puramente econômica, aliás, a "ameaça" das assimetrias não apresenta a mesma relevância estrutural, se pensada fora de um esquema de capitalismo "nacional". Com efeito, os economistas deduzem uma situação de maior racionalidade econômica intrínseca quando um país industrialmente menos desenvolvido associa-se, em esquema de livre-comércio, a um parceiro mais poderoso, não quando dois ou mais países igualmente "subdesenvolvidos" empreendem a construção de um "mercado comum". Daí as freqüentes críticas de economistas "liberais" ao esquema do Mercosul, manifestando eles a opinião de que 
o Brasil deveria abrir-se diretamente aos EUA num exercício de comércio preferencial, pois tal situação conferiria mais vantagens a sua economia menos avançada, ademais de permitir o desenvolvimento das especializações produtivas. Na prática, como já constatamos, as situações de livre-comércio nunca são perfeitas, persistindo espaços de liberalização restrita e diversos mecanismos de proteção setorial que inviabilizam o pleno jogo da movimentação de fatores idealizada pelos economistas teóricos.

Não se trata de uma questão que possa ser resolvida in abstracto, podendo apenas ser equacionada no terreno concreto das negociações para a definição das regras da futura zona de livre-comércio hemisférica, assim como no domínio bem mais prático (e microeconômico) das associações produtivas que serão promovidas voluntariamente pelas próprias empresas, independente da vontade dos governos. Com efeito, as empresas, conhecendo o cenário ambiental em que terão de atuar em determinado setor, antecipam-se às medidas governamentais de "imposição" de novas regras, construindo alianças táticas e acordos pragmáticos com competidores e parceiros em seu setor de atividade, atuando assim para reduzir de modo progressivo tais assimetrias. Esse processo será tão mais rápido quanto mais desregulado e aberto for o mercado setorial em questão.

Não é certo, por exemplo, que empresas brasileiras e as do Mercosul sejam invariavelmente menos atuantes do que as dos EUA em todos os setores abertos à competição, assim como não é seguro que o diferencial mercadológico em favor das empresas multinacionais seja válido em todas as situações de acesso e de penetração em novos mercados. Segmentação da demanda, disponibilidade de fatores, apresentação dos produtos, identificação cultural e sobretudo capacidade adaptativa e imaginação criadora podem atuar em proveito de empresas locais em certas áreas de bens e serviços. O Brasil, historicamente, já demonstrou possuir uma enorme capacidade de "digestão" de novas tendências e de novas técnicas produtivas, não havendo razão para acreditar que ele não saberá responder ao desafio que a Alca coloca para o seu sistema produtivo e para a sua capacidade inovadora. A passividade e o fatalismo nunca foram traços da personalidade brasileira.

Resumindo: a Alca possui, sem dúvida, certo potencial "destruidor" de empregos, em função das diferenças reais ou presumidas, de escala e de produtividade, entre as economias hemisféricas, assim como pelo fato de ela estender-se a uma gama tão ampla de setores que ultrapassa, por vezes, a capacidade "balanceadora" e a missão "restauradora" das condições "normais" de competição por parte dos governos nacionais. Sem embargo, os perigos são mais aparentes do que reais, uma vez que o próprio setor privado encontrará soluções pragmáticas a tais assimetrias, que representam outras tantas oportunidades para ganhos temporários antes que a liberalização regional converta-se em verdadeiro processo de globalização. Nesse caso, o excesso, ou a tentativa, de regulação governamental pode dificultar, mais do que facilitar, o processo de superação das assimetrias existentes.

Meio ambiente e normas laborais são fatores limitantes e negativos no esquema de negociações hemisféricas?; tais cláusulas vão bloquear a expansão do comércio ou o livre fluxo dos investimentos? - Tais normas, a exemplo das barreiras técnicas e outras medidas não-tarifárias que limitam ou obstaculizam o pleno acesso aos mercados, podem efetivamente constituir fatores limitantes a uma verdadeira liberalização hemisférica, pois que confirmando, se implementadas com base em uma visão exclusivamente nacional da questão, o sistema de "arquipélago de economias" que caracterizou, durante muito tempo, a economia internacional. A dificuldade não está tanto na fixação de determinado padrão, supostamente mais elevado, para equacionar problemas no campo trabalhista e na proteção do meio ambiente - algo continuamente tentado nos foros multilaterais -, mas em sua utilização abusiva, de forma unilateral, para bloquear a livre movimentação de bens, serviços e de capitais e tecnologias, inclusive mediante o recurso a sanções de natureza comercial. Essa possibilidade deve ser simplesmente vetada na mesa de negociações, pois que correspondendo a uma reação protecionista dos que desejam "fazer girar para trás a roda da história", ou seja, impedir que o capital dissemine-se pelo planeta, aproveitando as melhores chances de custo-benefício para uma alocação "ótima" de recursos.

Parece ocorrer, nesse particular, uma curiosa colusão de interesses e de propósitos entre sindicalistas do Norte e seus contrapartes do Sul, entre ONGs de ecologistas das duas pontas do continente americano, entre refratários pragmáticos (por definição de direita) e opositores ideológicos (geralmente de esquerda) ao livre-comércio, ademais da já conhecida (e pouco santa) aliança entre antiglobalizadores de todos os quadrantes do hemisfério. Normas laborais e ambientais converteram-se no terreno comum de luta de todos os que se posicionam contrariamente à Alca, seja pelos nobres motivos da defesa efetiva do meio ambiente e dos direitos humanos, seja por aqueles bem mais interessados (e por vezes mais mesquinhos) 
da defesa do emprego local ou de uma idílica produção saudável (e subsidiada), em fazendas familiares supostamente protegidas da concorrência selvagem introduzida pelas variedades geneticamente modificadas. O mais estranho, certamente, é ver sindicalistas do Sul defendendo empregos no Norte - uma vez que a introdução de normas laborais tem precisamente como objetivo impedir a "fuga" do capital, e portanto a transferência de empregos ao sul do Rio Grande - ou ecologistas, normalmente contrários à desigualdade inerente às estruturas econômicas internacionais, promovendo o protecionismo agrícola nos países desenvolvidos ou a manutenção involuntária de populações inteiras de coletores-extrativistas nas regiões tropicais em níveis próximos da miséria absoluta.

A formulação tentativa e a promoção ativa de normas e padrões ambientais e laborais mais avançados, quando combinada aos estímulos adequados para a livre circulação de fatores, inclusive da mão-de-obra, pode no entanto atuar como elemento de melhoria nos padrões de vida da maioria da população, sobretudo nos países ainda em desenvolvimento, servindo para elevar a produtividade do trabalho e a performance geral das economias mais atrasadas. Sua vinculação a acordos de comércio tem a virtude, porém, de bloquear a disseminação desses mesmos padrões que seus promotores querem ver implementados, uma vez que dificulta a mobilidade do capital e a transferência de tecnologia pela simples razão de inibir os fluxos de comércio, em lugar de estimulá-los.

Resumindo: um sistema de códigos de conduta, de caráter voluntário, mas de adesão progressiva, para padrões ambientais e laborais pode permitir superar situações de bloqueio "psicológico" que vêm contribuindo para contaminar o ambiente negociador da Alca. Quanto ao Brasil, consciente das limitações, mas também dos enormes progressos realizados nessas áreas, não parece ter algo a temer baseado na fixação de metas mais ambiciosas nos terrenos social e ambiental. A fixação de metas indicativas para a adesão progressiva dos países, mais do que a determinação de padrões uniformes para todos numa escala sincrônica de tempo, pode servir para reconciliar o capital e o trabalho, assim como ecologistas e empresas.

Práticas abusivas de salvaguardas comerciais e de antidumping, assim como políticas deliberadamente distorcivas das condições de comércio, a exemplo das medidas de apoio interno na área de agricultura, podem falsear os resultados da Alca, tornando o exercício liberalizador meramente retórico e desequilibrado? - Certamente, o Brasil e o Mercosul devem atuar com toda a determinação possível para eliminar as práticas mais danosas à liberdade de comércio nos terrenos em que ele apresenta uma competitividade "natural" bastante superior à do parceiro supostamente mais poderoso. Os EUA, com efeito, já declararam que pretendem deixar intocada, no processo de negociações da Alca, sua panóplia de medidas de defesa comercial, numa postura contraditória com o espírito de qualquer negociação multilateral, na qual todos os elementos possuindo incidência nos fluxos de comércio devem ser honestamente objeto de exame e eventual discussão quanto a sua adequação ao novo espaço econômico integrado.

Esse posicionamento tem menos a ver com a suposta consistência desses mecanismos nacionais de defesa comercial com as regras do GATT do que com o elemento de chantagem política exercido pelo Congresso contra a liberdade de ação dos negociadores do Executivo dos EUA. Trata-se de elemento puramente político, não sustentável em qualquer critério econômico de competição leal e de abertura negociada de mercados, e inteiramente dependente do exercício de uma efetiva capacidade negocial que deve poder manifestar-se no caso do Mercosul e do Brasil em particular.

Resumindo: um acordo de livre-comércio hemisférico no qual determinados componentes da agenda permanecem unilateralmente inegociáveis - uma reprodução econômica do conhecido aforismo orwelliano segundo o qual no "socialismo comercial" todos são iguais, mas alguns são "mais iguais do que outros" - não parece corresponder aos princípios aprovados em Belo Horizonte, em 1997, quanto ao equilíbrio de resultados e ao compromisso indivisível em benefício de todos.

A Alca conduzirá à desnacionalização da economia brasileira? Subsistirão políticas setoriais em nível nacional, diminuirá a margem de liberdade alocada à política econômica governamental? - A eventual "desnacionalização" - não de setores, mas de frações de mercados setoriais - com base na venda ou fusão de empresas brasileiras a gigantes estrangeiros não será diferente ou em todo caso maior do que já ocorre no âmbito do processo de globalização atualmente em curso, que foi voluntariamente assumido pelo Brasil como um desafio importante a ser vencido, não como uma ameaça a ser evitada. Em nenhum dos processos conhecidos de ativa interdependência econômica, como são os existentes no âmbito da OCDE e a fortiori no seio da UE, diminuiu o papel do Estado ou se enfraqueceu a economia nacional, pela simples razão de que o capital estrangeiro passou a participar com maior intensidade dos esquemas produtivos in- 
ternos e dos circuitos locais de produção e distribuição. Ao contrário, as "pequenas" empresas locais adquirem dimensão nacional e, então, passam a atuar no plano internacional, constituindo um "capitalismo multinacional" que foi até agora o apanágio dos países mais avançados. Ocorreu assim nos casos de Portugal e Espanha, assim como da Itália, e não há porque descartar que tais processos venham a ocorrer igualmente no âmbito do Brasil e do Mercosul.

O Brasil tem, por certo, um crônico problema de déficit em transações correntes e de desequilíbrio na balança de pagamentos, que acompanharam todo o seu processo de industrialização. Entretanto, tais fragilidades estão igualmente associadas ao ambiente geral dos negócios, mais do que à ausência de capacidade reguladora do Estado, que assumirá formas novas num cenário mais previsível de planejamento microeconômico. $\mathrm{O}$ fato de que parceiros estrangeiros passem a atuar em setores antes vedados ou mais limitados à presença de multinacionais não se traduz necessariamente numa desintegração automática das cadeias produtivas, antes numa integração destas a circuitos mais amplos nos planos hemisférico ou mundial.

É evidente, por outro lado, que qualquer acordo internacional que se faça em áreas ainda inéditas de regulação multilateral ou regional, como é o caso da Alca - que parece apontar para um instrumento relativamente "intrusivo" como políticas setoriais ou de mecanismos regulatórios redunda numa diminuição da esfera da soberania absoluta dos Estados nacionais e na redução ulterior dos poderes regulatórios dos legisladores econômicos e, na outra vertente, num aumento do grau de interdependência das economias e da margem de liberdade alocada aos agentes econômicos privados. Contudo, isso é próprio das tendências atuais tanto do regionalismo, como do multilateralismo econômico, assim como da própria agenda negociadora internacional, das quais participa o Brasil em plena consciência de causa e tendo sempre como critério absoluto de atuação o interesse nacional na matéria. Entre esses critérios não se situa o de privilegiar o capital estrangeiro em detrimento do capital nacional, mas em atribuir a ambos um ambiente regulatório relativamente uniforme quanto às regras gerais de exercício da atividade, o que é conhecido em terminologia "gattiana" como tratamento nacional.

Resumindo: a internacionalização da economia brasileira e a constituição de firmas nacionais de dimensão internacional - algo presumivelmente desejado, mesmo pelo mais ferrenho opositor da Alca e do capitalismo norteamericano - se dará, não no quadro de um suposto pro- cesso de "preparação" da economia brasileira para "enfrentar a concorrência externa" - período de tempo que é sempre indefinido e invariavelmente dependente de condições “ótimas” de políticas macroeconômicas, comercial e industrial, que nunca se realizam na prática -, mas no próprio bojo da globalização, seja ela restrita ao hemisfério ou ampliada em escala planetária. Processos de "acumulação primitiva" nunca ocorreram de fato, a não ser nas análises ex-post que tendem a racionalizar a experiência histórica e a oferecer como "modelo" o que nunca passou de um processo único e original como desenvolvimento socioeconômico de determinada formação nacional. ${ }^{2}$

O Brasil estaria isolado se decidisse permanecer fora da Alca? - Trata-se de uma decisão inteiramente política, de acordo com uma hipótese extrema, mas que será tomada com base numa análise econômica e diplomática no curso do processo negociador. A Alca não é o único processo negociador de que participam ou participarão o Brasil e o Mercosul, bastando mencionar o processo bi-regional com a União Européia, os entendimentos no contexto da África austral e a opção preferencial no âmbito da América do Sul. As opções para o Brasil e para o Mercosul não estão fechadas, como alguns cenários mais pessimistas parecem antecipar. É bem mais provável, aliás, não existir uma Alca, por razões que não teriam nada a ver com a oposição ou relutância brasileira (mas mais provavelmente com a relutância do Congresso e do próprio Executivo dos EUA), do que ser concluída uma Alca sem a participação do Brasil.

Uma revisão de meio século do multilateralismo econômico e político revela que nenhum país de dimensões "respeitáveis", seja ele "atrasado", seja desenvolvido, permanece isolado no cenário internacional. A experiência histórica da China, da Índia, da Rússia, e dos próprios países desenvolvidos ocidentais, a começar pelos EUA e passando pelos grandes da Europa - hoje unidos no mais exitoso experimento de integração já conhecido - confirma que o isolamento é uma fase temporária e passageira de qualquer processo de emergência e consolidação de novas estruturas de poder econômico e político mundial. A posição do Brasil em relação ao sucesso - ou fracasso - das negociações da Alca não deveria fugir a essa regra não escrita da diplomacia contemporânea. O Congresso dos EUA, aliás, teria provavelmente maior responsabilidade nesse eventual fracasso, do que uma suposta "intransigência" do Itamaraty ou do Governo brasileiro. Muito depende, em todo caso, da capacidade negociadora da diplomacia brasileira no terreno da barganha concreta em torno da Alca, bem como 
de sua capacidade "explicativa" em direção dos públicos externo e interno. Nesse particular, o Brasil - dotado de uma diplomacia econômica que deita raízes nas primeiras décadas do século XIX - pode considerar-se bem servido e dispondo de enormes vantagens comparativas em relação a vários outros países do continente.

\section{NOTAS}

1. A retomada do ciclo da globalização capitalista, numa paródia ao Manifesto de 1848, foi analisada no livro de Almeida (1999).

2. Este último ponto apresenta certa importância (teórica) do ponto de vista da sociologia do desenvolvimento econômico, mas tem pouca relevância prática do ponto de vista do negociador governamental ou do estadista, que precisam responder às preocupações de suas respectivas clientelas, sempre inquietas com qualquer tipo de penetração estrangeira na economia nacional.

\section{REFERÊNCIAS BIBLIOGRÁFICAS}

ALMEIDA, P.R. de. Formação da diplomacia econômica no Brasil: as relações econômicas internacionais no império. São Paulo, Senac-Funag, 2001.

Velhos e novos manifestos: o socialismo na era da globalização. São Paulo, Juarez de Oliveira, 1999.

Paulo Roberto de Almeida: Doutor em Ciências Sociais. Autor de Formação da Diplomacia Econômica no Brasil (pralmeida@mac.com). 